\title{
Investigating the Association between Strategic and Pathological Gambling Behaviors and Substance Use in Youth: Could Religious Faith Play a Differential Role?
}

\author{
Grace P. Lee, MHS, ${ }^{1}$ Lilian A. Ghandour, PhD, MPH, ${ }^{2}$ Alaa H. Takache, $\mathrm{MPH},{ }^{2}$ \\ Silvia S. Martins, MD, $\mathrm{PhD}^{1,3}$ \\ ${ }^{1}$ Department of Mental Health, Johns Hopkins Bloomberg School of Public Health, Baltimore, Maryland \\ ${ }^{2}$ Department of Epidemiology and Population Health, American University of Beirut, Beirut, Lebanon \\ ${ }^{3}$ Department of Epidemiology, Columbia University Mailman School of Public Health, New York, New York
}

Objectives: This study investigated the link between gambling behaviors and the use of alcohol, drugs, and nonprescribed prescription medications, while exploring the moderating role of distinct religious faiths.

Methods: In 2010, 570 students from the American University of Beirut completed a self-reported, anonymous English questionnaire, which included lifetime gambling and past-year substance use measures.

Results: Half (55\%) were lifetime gamblers, of whom, $12 \%$ were probable pathological gamblers. About $60 \%$ were strategic gamblers. Lifetime gamblers were more than twice as likely as nongamblers to report past-year illegal drug use and alcohol abuse. Probable pathological gamblers were also more than four times as likely as nongamblers to report nonmedical prescription drug use, illegal drug use, and alcohol abuse. Compared to nonstrategic gamblers, strategic gamblers had more than three times the odds of illegal drug and cigarette use. The link between alcohol abuse and gambling was stronger among Christians than Muslims. Conversely, Muslims were more likely to report the co-occurrence of various gambling behaviors (lifetime, probable pathological, and strategic gambling) with both illegal drug use and cigarette use.

Conclusions: Gambling and substance use behaviors were strongly linked in this sample of youth from Lebanon, corroborating the evidence from North America. Particularly novel are the cooccurrence of pathological gambling and nonmedical prescription drug use and the potential differential role of religion. (Am J Addict 2014;23:280-287)

Received July 6, 2012; revised March 11, 2013; accepted June 9 , 2013.

Address correspondence to Ghandour, Department of Epidemiology and Population Health, Faculty of Health Sciences, American University of Beirut, Office: Room 207, Van Dyck, PO Box 110236, Riad El-Solh 1107-2020, Beirut, Lebanon. E-mail address: 1g01@aub.edu.lb.

\section{INTRODUCTION}

Gambling venues and opportunities have become increasingly accessible and normalized. Such gambling expansion is especially relevant to youth raised in environments where gambling is glorified, heavily and widely marketed, and viewed as a common recreational activity. ${ }^{1}$ More importantly, excessive gambling can lead to the development of pathological gambling, which is associated with many adverse outcomes including financial, ${ }^{1}$ interpersonal, ${ }^{2}$ criminal, ${ }^{1}$ academic, ${ }^{1}$ and psychiatric problems. ${ }^{3}$ Gambling among college students is particularly problematic as a meta-analysis had found the lifetime prevalence of pathological gambling to be highest among college students. ${ }^{4}$

To date, gambling studies among college students are predominantly from North America, and show a lifetime gambling prevalence of $67-97 \% .^{5,6}$ A meta-analysis of North American college gambling studies further reports that 5-14\% of college students are pathological gamblers. ${ }^{7}$ One study from New Zealand on 171 college students similarly found $97 \%$ to be past-year gamblers and $15 \%$ to be pathological gamblers. ${ }^{8}$ Such heightened prevalence of pathological gambling could support the developmental psychology notion that college students are a unique group of emerging adults marked by heightened risk-taking, identity exploration, instability, selffocus, and self-exploration without the parental and social controls from adolescence. ${ }^{9}$

Further highlighting the public health significance of gambling and pathological gambling among college students is their high co-occurrence with substance use ${ }^{5,6}$ For instance, among 1,350 college students across four U.S. universities, pathological gamblers were more likely than both social and nongamblers to binge drink, smoke cigarettes, and use marijuana. ${ }^{6}$ Similarly, strategic gambling activities (e.g., card games, sports betting) have been found to be positively associated with substance use. ${ }^{10}$ For instance, the U.S.- 
conducted Gambling Impact and Behavior ${ }^{10}$ study on adults, found a higher prevalence of strategic gambling among moderate/high frequency alcohol users than among abstainers/ low frequency alcohol users.

Altogether the evidence points to several gaps in the literature. First, the few existing college gambling studies are primarily from North America, creating a need for more research from other countries/cultures. Moreover, to our knowledge, no other study has investigated the association between gambling and the nonmedical use of prescription medications, or between strategic gambling and substance use, specifically among college youth. This renders the current study on youth gambling from Lebanon quite important, especially given the country's several particularities. First, Lebanon is a small country in the Middle East positioned at the crossroad between western and eastern cultures. It is also home to two of the world's major religions (ie, Christianity and Islam), each with a distinct viewpoint on gambling. While the Christian Biblical scripture strongly discourages notions relevant to gambling (e.g., idolatry, fortune-telling, greed), gambling is explicitly and strictly prohibited in Islam: 'They ask thee concerning wine and gambling. Say: "In them is great sin, and some profit, for men; but the sin is greater than the profit" (verse 219 of Surah 2 of the Qur'an). Furthermore, Lebanon is home to the Middle East's largest casino, Casino $\mathrm{Du}$ Liban, and to numerous other amusement centers that are neither regulated nor documented. Lottery tickets and scratch games are also widely available, cheaply sold, and not governed by a minimal legal purchasing age.

This study therefore presents a unique opportunity to examine the association between various gambling behaviors and the use of substances, and the possible moderating role of religion, within an ethnically and religiously diverse sample of college students from Lebanon. Specifically, the article aims to: (1) describe the lifetime prevalence of any, strategic and pathological gambling; (2) examine the co-occurrence of gambling behaviors and the past-year use of various substances; and (3) explore religious differences in the cooccurrence of gambling and substance use.

\section{METHODS}

\section{Participants}

A cross-sectional sample of graduate and undergraduate students from the American University of Beirut (AUB), a large private university in Beirut, was selected using a proportionate cluster sampling technique to represent all faculties and levels of education (both undergraduate and graduate). Of the classrooms selected, $52 \%$ of the professors agreed to participate, and $86 \%$ of the participating classrooms' students completed the survey. The final sample $(n=570)$ comprised $60 \%$ of the selected students.

\section{Instrument and Measures}

A self-completed, anonymous questionnaire in English was administered during regular class hours. Students read and agreed to a written informed consent form that described the objectives of the study, the survey's anonymity (ie, absence of personal identifiers) and confidentiality (i.e., data available to the research team only), and the respondents' right to refuse participation or answer any question. The study design, instruments, and informed consent were granted ethical approval by the university's Institutional Review Board (IRB).

\section{Sociodemographics and Religion}

Sociodemographics such as gender, age, nationality, perceived socio-economic status (SES), school affiliation, and present living arrangement were collected. Religious affiliation (i.e., Muslim or Christian) and the frequency of their religious practice (i.e., regularly, sometimes, or rarely/never) were also collected.

\section{Lifetime Gambling}

Students reported whether they had ever engaged in each of the 11 gambling activities listed (i.e., cards, slots, roulette, bingo, dice, sports betting, horse betting, stock, playing pool/ bowling for money, lottery tickets, and internet). Individuals that engaged in at least one activity were considered lifetime gamblers. Strategic gamblers were lifetime gamblers who engaged in any of the following activities: cards, sports betting, horse betting, and playing pool/bowling for money. The 20item South Oaks Gambling Screen (SOGS) screened for gambling disorders. ${ }^{11}$ The current study excluded two SOGS items (i.e., borrowing money to gamble or to pay gambling debts from loan sharks; borrowing money to gamble or to pay gambling debts from your checking accounts by passing bad checks) due to perceived cultural irrelevance. Gamblers with a SOGS score of $0-2$ were labeled as having no/minimal gambling problems (i.e., social gamblers or SG). A score of 3 or 4 denoted problem gambling, and possible pathological gamblers scored at least 5. Due to the small numbers, and the similar clinical profiles among problem and possible pathological gamblers, ${ }^{10}$ the two groups will be collectively referred to as "probable pathological gamblers (PPG)." The SOGS has demonstrated satisfactory internal consistency reliability (Cronbach's alpha $=0.97$ ) and validity in four different samples, including university students. ${ }^{11}$

\section{Past-Year Substance Use}

Self-reports of past-year regular cigarette use (i.e., a cigarette every day for at least 1 month), alcohol use (i.e., a glass of wine, a bottle of beer, a mixed drink, a shot of liquor), illegal drug use (i.e., marijuana, ecstasy, cocaine/crack, heroin, LSD, inhalants), and nonmedical prescription drug use (NMPDU; i.e., sleeping pills, anxiety medication, opioid pain relievers, stimulants) were collected. NMPDU was defined as using a prescription drug originally prescribed for somebody else, or for longer periods than prescribed, or for reasons other than what the medication is intended for. ${ }^{12}$ Both the definition and questions defining NMPDU were adapted (following author permission) from McCabe and co-workers' published works. ${ }^{12-15}$ Past-year alcohol users went on to 
complete a checklist of items from the Diagnostic Statistical Manual 4th Edition (DSM-IV) to screen for alcohol abuse. Those who fulfilled at least one of the diagnostic criteria (i.e., failure to fulfill a major role obligation, alcohol-related legal problems, recurrent social/interpersonal problems, and under the influence in physically hazardous situations) were categorized as alcohol abusers. The test-retest reliability of the DSM-IV alcohol abuse diagnoses have been demonstrated to be $0.70-0.84$ among samples of international and U.S. general populations. ${ }^{16,17}$

\section{Data Analysis}

Exploratory data analyses were conducted using Pearson's Chi-square tests. To answer our research questions, both binary and multinomial logistic regression models were run, adjusted for sociodemographics. First, regression models were run to examine the associations between lifetime gambling behaviors (i.e., any gambling, strategic gambling, and probable pathological gambling) and past-year substance use (i.e., NMPDU, illegal drug use, cigarette use, alcohol use, alcohol abuse) in the total sample. Given the differences in stance on gambling and alcohol between the Muslim and Christian religions, stratified analyses were conducted to examine potential religious differences in the aforementioned associations. Given our "a priori" theoretical basis for producing stratum-specific estimates, and the fact that $p$-values for the test of heterogeneity are neither necessary nor sufficient for the evaluation of true subgroup differences ${ }^{18}$ stratum-specific findings (estimate and its $p$-value) are used as a basis for examining/interpreting potential differences by religious faith; it is worth noting that the 95\% confidence interval (CI) for all estimates are additionally provided as an indication of the precision of the estimate, not for hypothesis testing. All analyses were adjusted for gender, age, perceived SES, nationality, school affiliation, religion, practice of faith, and residence. Complex survey data analyses accounted for sampling weights (i.e., faculty, grade level) and the primary sampling unit (i.e., classroom). The alpha level was set at 0.05 . Analyses were performed using Stata MP $12 .{ }^{19}$

\section{RESULTS}

\section{Sociodemographics and Gambling Prevalence}

Most of the participating 570 AUB students were between ages 19-21 years, Lebanese, and Muslim (Table 1). Muslim students were significantly more likely than Christians to practice their faith regularly (Muslims: 56.4\%; Christians: $43.1 \%$ $p<.001)$. However most of the sample considered religion to be important with no observed statistically significant differences (Muslims: $86.9 \%$; Christians: $82.0 \% p=.33$ ).

Approximately half of the sample $(54.7 \% ; n=297)$ was lifetime gamblers and $4.8 \%(n=27)$ were lifetime probable pathological gamblers (PPG; $11.8 \%$ of lifetime gamblers). Strategic gambling was reported by $57.9 \%(n=172)$ of the lifetime gamblers. As shown in Table 1, the prevalence of lifetime, social, probable pathological, and strategic gambling were higher among males, School of Business students, and Christians. Students who rarely/never practiced their faith were more likely to report lifetime, social, and probable pathological gambling. Lifetime gambling was also more likely among the 19-21 age group and dual citizens. Students who believed their families were richer than most and lived in apartments alone or with partners were more likely to report any strategic gambling.

\section{Religious Differences in the Associations Between Gambling Behaviors and Substance Use Lifetime Gambling}

In the total sample, the prevalence of all substance use except NMPDU was significantly higher among lifetime gamblers than nongamblers (Table 2). Logistic regression models that adjusted for sociodemographics however, found that only the associations with illegal drug use $(\mathrm{aOR}=4.09$; $[1.33,12.53] ; p=.02)$ and alcohol abuse $(\mathrm{aOR}=2.60$; $[1.18,5.74] ; p=.02)$ remained.

Turning to the religion-stratified results, again, NMPDU was not related to lifetime gambling. Illegal drug use, however, was associated with a sevenfold increase in odds of lifetime gambling among Muslims $(p=.002)$ versus a twofold nonstatistically significant increase among Christians $(p=.35)$, controlling for sociodemographics (Table 2). Worth noting here is the twofold difference in illegal drug among nongamblers for Christians relative to Muslims, versus a relatively similar prevalence of illegal drug use among gamblers within both religious groups (17.9\% and $21.7 \%$, respectively).

Any alcohol use was statistically significantly associated with higher adjusted odds of lifetime gambling in Muslims only. Not only did Muslims report a lower prevalence of alcohol use, but significantly more Muslim gamblers than nongamblers $(53.1 \%$ vs. $22.9 \%)$ also reported any alcohol consumption (Table 2). Moreover, the prevalence of past-year alcohol abuse among Muslim gamblers was approximately four times that of nongamblers $(25.6 \%$ vs. $5.7 \%)$ versus a twofold difference in Christian gamblers (36.6\% vs. $16.1 \%$ ). After accounting for their sociodemographics however, a fourfold increase in odds ( $p=.001)$ was only observed among Christians (Table 2).

\section{Lifetime Probable Pathological Gambling}

In the total sample, the past-year prevalence of all substances was highest among PPG, followed by SG, then nongamblers (Table 2). Adjusted for students' sociodemographics, and compared to nongamblers, SG and PPG were both more likely to report illegal drug use and alcohol abuse; PPG were additionally at higher odds of NMPDU (Table 2).

With regards to religious differences, the odds of NMPDU among PPG were approximately three times higher in Muslims compared to Christians (Table 2). Moreover, Illegal drug use was more prevalent in Muslim than Christian PPG (compared to nongamblers of both religious groups) and remained so upon sociodemographic adjustment. Both the prevalence and adjusted odds of alcohol abuse among PPG were also higher among Christian than Muslim students. 


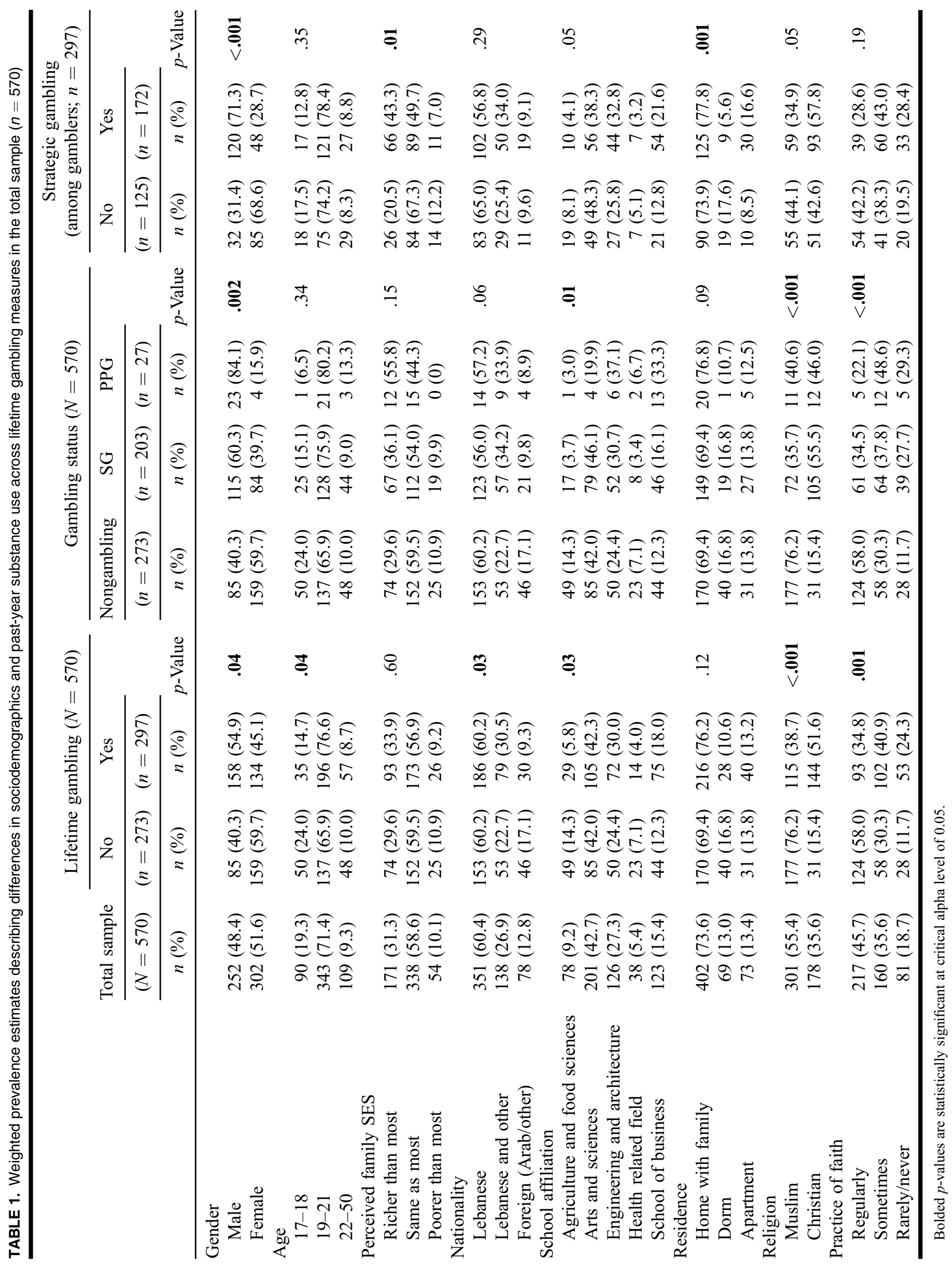




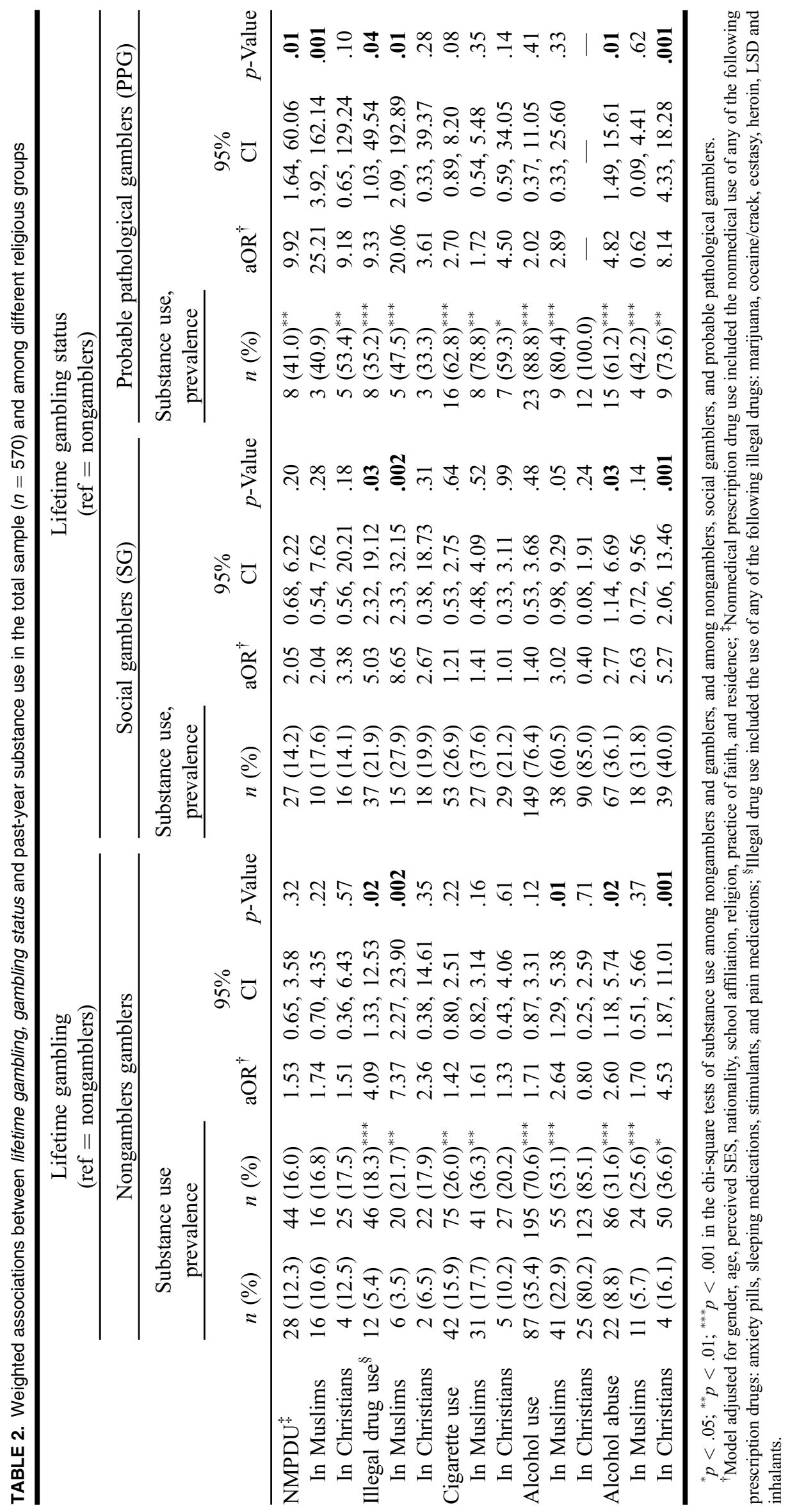




\section{Lifetime Strategic Gambling Among Gamblers}

Among lifetime gamblers, significantly more strategic gamblers than nonstrategic gamblers reported all substance use except NMPDU (Table 3). However, upon controlling for students' sociodemographics, strategic gambling was positively associated with illegal drug and cigarette use only (Table 3 ). Both illegal drug use and cigarette use were more prevalent in Muslim versus Christian strategic gamblers (Table 3).

Alcohol use was common among both Christian nonstrategic $(71.9 \%)$ and strategic gamblers $(91.8 \%)$ while the prevalence of alcohol use among Muslim strategic gamblers was approximately double that of Muslim nonstrategic gamblers $(71.0 \%$ vs. $32.3 \%)$. While the adjusted odds of alcohol use were three times higher among the Muslim strategic versus nonstrategic gamblers, the finding was not statistically significant. Similarly, alcohol abuse in Muslim (43.0\%) and Christian (49.3\%) strategic gamblers was similarly prevalent, while the prevalence in Muslim nonstrategic gamblers was approximately half that of Christians $(5.9 \%$ vs. $11.6 \%$ ). As such, the adjusted association between pastyear alcohol abuse and lifetime strategic gambling was higher among Muslims, again though not statistically significant.

\section{DISCUSSION}

The current study, the first of its kind from Lebanon and the Arab region, suggests that 1 in 2 university students have ever gambled. While most were social gamblers, 1 in 10 of the gamblers were probable pathological gamblers. Nonetheless, the lifetime gambling prevalence in the current sample is lower than that found among its Western counterparts (e.g., ${ }^{5,8}$ ), possibly due to the high percentage of Muslims in the current study. Since Islam strictly prohibits gambling, it is not surprising that most Muslim students are nongamblers. Still, the probable pathological gambling prevalence among the Lebanese students is similar to that of North American students. ${ }^{4,8}$

Consistent with findings from North American college students, ${ }^{5}$ the current study found strong links between lifetime, social, and probable pathological gambling and past-year illegal drug use and alcohol abuse. A novel finding was that probable pathological gamblers were more likely than nongamblers to report past-year nonmedical prescription drug use (NMPDU). While Currie et al. ${ }^{20}$ found similar results among Canadian adults, the current study appears to be the first to examine such a relationship among college students. This observation is important because NMPDU is currently a major global public health concern, with young adults reporting the highest prevalence of misuse. ${ }^{12,21}$ Furthermore, recent reports suggest that NMPDU may be increasing among the Lebanese to cope with distress resulting from the irregular invasions, internal conflicts, and political instability. ${ }^{22}$ Studies have similarly suggested gambling to be a form of self-medication. ${ }^{23}$ Thus, the current sample's probable pathological gamblers could have viewed both gambling and NMPDU as means of escape.

TABLE 3. Weighted association between any strategic gambling and past-year substance use among lifetime gamblers $(\mathrm{n}=297)$ and different religious groups

\begin{tabular}{|c|c|c|c|c|c|}
\hline & Nonstrategic (ref) & Strategic & & & \\
\hline & Substance & alence & & & \\
\hline & $n(\%)$ & $n(\%)$ & $\mathrm{aOR}^{\dagger}$ & $95 \% \mathrm{CI}$ & $p$-Value \\
\hline $\mathrm{NMPDU}^{\dagger}$ & $19(12.3)$ & $25(18.4)$ & .90 & $0.31,2.64$ & .84 \\
\hline In Muslims & $7(14.1)$ & $9(19.2)$ & .99 & $0.24,4.03$ & .99 \\
\hline In Christians & $10(12.2)$ & $15(20.1)$ & .91 & $0.18,4.69$ & .91 \\
\hline Illegal drug use $\mathrm{f}^{\S}$ & $6(6.5)$ & $40(27.1)^{* *}$ & 9.35 & $1.12,7.74$ & .04 \\
\hline In Muslims & $3(8.5)$ & $17(34.7)^{*}$ & 5.35 & $0.98,29.0$ & .05 \\
\hline In Christians & $2(5.3)$ & $20(24.9)^{*}$ & 1.86 & $0.12,28.8$ & .65 \\
\hline Cigarette use & $13(10.0)$ & $61(36.8)^{* * *}$ & 3.40 & $1.16,9.92$ & .03 \\
\hline In Muslims & $8(12.8)$ & $32(56.9)^{* *}$ & 5.75 & $1.08,10.63$ & .04 \\
\hline In Christians & $4(9.1)$ & $23(25.8)$ & 1.07 & $0.14,8.30$ & .95 \\
\hline Alcohol use & $59(52.1)$ & $143(84.4)^{* * *}$ & 1.68 & $0.48,5.80$ & .40 \\
\hline In Muslims & $14(32.3)$ & $40(71.0)^{* *}$ & 3.06 & $0.77,12.25$ & .11 \\
\hline In Christians & 37 (71.9) & $86(91.8)^{*}$ & .97 & $0.21,4.47$ & .97 \\
\hline Alcohol abuse & $10(9.2)$ & $76(46.9)^{* * *}$ & 2.69 & $0.84,8.58$ & .09 \\
\hline In Muslims & $2(5.9)$ & $22(43.0)^{* *}$ & 2.84 & $0.92,8.73$ & .07 \\
\hline In Christians & $6(11.6)$ & $44(49.3)^{* *}$ & 2.04 & $0.32,13.18$ & .44 \\
\hline
\end{tabular}

${ }^{*} p<.05 ;{ }^{* *} p<.01 ;{ }^{* * *} p<.001$ in the chi-square tests of substance use among nonstrategic gamblers and strategic gamblers.

${ }^{\dagger}$ Model adjusted for gender, age, perceived SES, nationality, school affiliation, religion, practice of faith, and residence; ${ }^{*}$ Nonmedical prescription drug use included the nonmedical use of any of the following prescription drugs: anxiety pills, sleeping medications, stimulants, and pain medications; ${ }^{\S}$ Illegal drug use included the use of any of the following illegal drugs: marijuana, cocaine/crack, ecstasy, heroin, LSD and inhalants. 
It was also important to distinguish strategic gamblers from nonstrategic gamblers because studies have found the former to experience worse outcomes, such as the development of pathological gambling. ${ }^{5}$ The current study found strategic gamblers to be more likely than nonstrategic gamblers to report past-year illegal drug use, cigarette use, and alcohol abuse. While the current study, to our knowledge, was the first to examine the association between strategic gambling and substance use in college students, our findings support past results from adult populations. ${ }^{24}$

A novelty to the extant literature is the possible differential role distinct religious faiths may play on gambling and its cooccurrence with other addictive behaviors. In the current sample, the prevalence of lifetime and pathological gambling, as well as past-year alcohol use and alcohol abuse were lower among Muslims than Christians. Similar differences were found among adults from other countries. ${ }^{25-27}$ Such religious differences are predominantly attributable to the strict prohibition of both gambling and alcohol use in the Qur'an compared to the Biblical discouragement of such behaviors. Christians' higher prevalence of co-occurring gambling and both alcohol use and abuse in the current sample, could further exemplify Christianity's relatively lenient view towards both behaviors as compared to Islam. Conversely, the co-occurrence of the various gambling behaviors and both illegal drug and cigarette use were higher among Muslims. According to the Problem Behavior Theory, ${ }^{28}$ problem behaviors (e.g., gambling, substance use) often co-occur within individuals. Furthermore, impulsivity is suggested to be the common factor among individuals with multiple problem behaviors. ${ }^{29}$ In fact, gambling, particularly pathological and strategic gambling, and substance use have been found to be correlated with high impulsivity among young adults. ${ }^{30-33}$ Thus the current finding of a stronger link between gambling and substance use in Muslims than Christians could be that Muslims who defy their religion and religious principles to engage in a prohibited activity could exhibit higher impulsivity than their non-Muslim peers, which could increase their risk of involvement in yet another prohibited activity.

Despite the study's originality, the findings need to be interpreted in light of a few limitations. Firstly, the relatively small sample size, particularly of each religious group, coupled with the low prevalence of the various substance use behaviors, particularly alcohol abuse, weakened estimate precision and limited at times the study's statistical power to detect statistically significant differences. However, the variations in the magnitude of the associations suggest that the observed differences indicate a true heterogeneity between the two religious groups. Furthermore, post-hoc analyses that further controlled for all substance use measures within the same model (not reported given potential multicollinearity; available upon request) produced similar results, thus providing further assurance regarding the validity of the current findings. Secondly, the absence of past-year gambling measures impeded examining the "co-occurrence" of gambling and substance use behaviors; nonetheless, the current findings are consistent with previous published findings, ${ }^{5}$ thus suggesting that the potential bias could be limited. The current study also lacked data on mental health, which could possibly have confounded some findings specific to probable pathological gamblers who tend to report poor mental health. ${ }^{34}$ Potential recall bias may have resulted due to the use of self-report lifetime measures of gambling; however, the use of an anonymous, self-report questionnaire may have decreased other sources of information bias (e.g., social desirability bias). While probable pathological gambling was assessed with the validated (though not in the current population) and commonly used SOGS,,${ }^{11}$ the exclusion of 3 of its 20 items combined with the missing data (i.e., $14 \%$ of the sample without any SOGS data) most likely underestimated the number of probable pathological gamblers. Nonetheless, the consistency of the current findings with those of other studies speaks to the construct validity of the SOGS measure in the current population, despite the missingness. Moreover, internet gambling was not considered as a type of strategic gambling given that details on the specific types of internet games the participants engaged in was not collected; the exclusion could have led to an underestimation of strategic gamblers as one study had previously found that two-thirds of internet gamblers tend to play strategic games. ${ }^{35}$ However, because only $5.6 \%$ of the current sample reported internet gambling, the underestimation should be minimal. Lastly, despite AUB's heterogeneous student population, the current findings, particularly prevalence estimates, may not generalize to other university students from Lebanon with different socio-economic or educational backgrounds. Findings on Muslims in this sample may also not generalize to other Muslims, given the university's mixed religious composition and ethnically diverse student population, as well as relatively middle-high SES. It is possible, therefore, that Muslims in this sample are more likely to be influenced by their non-Muslim peers' beliefs, attitudes, and behaviors, and have a greater purchasing capacity (be it for alcohol and/or gambling venues). It is worth noting that although information on religious sect was not collected, intra-religious differences are not expected given that conservative Protestants make up $<1 \%$ of the Lebanese Christian population, and differences within the Muslim faith are unlikely since all follow the Qur'an and its teachings as their book of divine guidance and direction. Quite importantly, however, the extent to which Muslim and Christian youth adhere to their religious principles however (i.e., practice of faith) was considered.

Not only is this the first epidemiological study to examine gambling among college students from the Middle East and Arab region, it is also the first to report a possible differential role for religion in a country with a religiously diverse population and where gambling is legalized. Nonetheless, more research using larger studies is needed to confirm the observed religious differences and begin to understand the underlying reasons as well as mechanisms of the observed differences between Muslims and Christians that are beyond the scope of the study. The needs of those experiencing 
gambling-related problems among Lebanese college students and youth must also be understood and met. Only by furthering the current knowledge of this vulnerable population of youth can pathological gambling prevalence be lowered via public policies and interventions that are both evidence-based and culturally relevant.

The authors would like to acknowledge the University Research Board at the American University of Beirut as the sole source of funding for this research study.

The authors would also like to extend their gratitude and appreciation to Ms. Donna El Sayed for her invaluable assistance in various stages of the study, as well as Ms. Reem Saad, Eleine Khoury, and Lynn Itani for their help in data collection.

\section{Declaration of Interest}

The authors report no conflicts of interest. The authors alone are responsible for the content and writing of this paper.

\section{REFERENCES}

1. Williams RJ, Connolly D, Wood RT, et al. Gambling and problem gambling in a sample of university students. $J$ Gambling Issues. 2006;16:1-14.

2. Korman LM, Collins J, Dutton D, et al. Problem gambling and intimate partner violence. J Gambl Stud. 2008;241:13-23.

3. Chou KL, Afifi TO. Disordered pathologic or problem. Gambling and axis I psychiatric disorders: results from the National Epidemiologic Survey on Alcohol and Related Conditions. Am J Epidemiol. 2011;17311:12891297.

4. Shaffer HJ, Hall MN, Vander Bilt J. Estimating the prevalence of disordered gambling behavior in the United States and Canada: A research synthesis. Am J Public Health. 1999;899:1369-1376.

5. Engwall D, Hunter R, Steinberg M. Gambling and other risk behaviors on university campuses. J Am Coll Health. 2004;526:245-255.

6. Lesieur HR, Cross J, Frank M, et al. Gambling and pathological gambling among university students. Addict Behav. 1991;166:517-527.

7. Blinn-Pike L, Worthy SL, Jonkman JN. Disordered gambling among college students: A meta-analytic synthesis. J Gambl Stud. 2007;232:175-183.

8. Clarke D. Gambling and the trait of addiction in a sample of New Zealand university students. NZ J Psychol. 2003;32:39-48.

9. Arnett JJ, Emerging adulthood. A theory of development from the late teens through the twenties. Am Psychol. 2000;555:469-480.

10. Potenza MN, Maciejewski PK, Mazure CM. A gender-based examination of past-year recreational gamblers. J Gambl Stud. 2006;221:41-64.

11. Lesieur HR, Blume SB. The South Oaks Gambling Screen SOGS: A new instrument for the identification of pathological gamblers. Am J Psychiatry. 1987;1449:1184-1188.

12. Johnston LD, O'Malley PM, Bachman JG, et al. Monitoring the future national survey results on drug use, 1975-2006. Volume II: College Students and Adults Age 19-45. Bethesda, MD: National Institute on Drug Abuse; 2007.

13. McCabe SE, Cranford JA, Boyd CJ, et al. Motives, diversion and routes of administration associated with nonmedical use of prescription opioids. Addict Behav. 2007;32:562-575.
14. Boyd CJ, McCabe SE, Teter CJ. Medical and nonmedical use of prescription pain medication by youth in a Detroit-area public school district. Drug Alcohol Depend. 2006;81:37-45.

15. McCabe SE, Boyd CJ. Sources of prescription drugs for illicit use. Addict Behav. 2005;30:1342-1350.

16. Chatterji S, Saunders JB, Vrasti R, et al. Reliability of the alcohol and drug modules of the alcohol use disorder and associated disabilities interview schedule—Alcohol/drug-revised (AUDADIS—ADR): An international comparison. Drug Alcohol Depend. 1997;47:171-185.

17. Grant BF, Dawson DA, Stinson FS, et al. The alcohol use disorder and associated disabilities interview schedule-IV (AUDADIS-IV): Reliability of alcohol consumption, tobacco use, family history of depression and psychiatric diagnostic modules in a general population sample. Drug Alcohol Depend. 2003;71:7-16.

18. Szklo M, Nieto FJ. Epidemiology Beyond the Basics. Gaithersburg, MD: Aspen Publishers; 2000.

19. StataCorp. Stata statistical software: Release 12.0; 2012.

20. Currie CL, Schopflocher DP, Wild TC. Prevalence and correlates of 12month prescription drug misuse in Alberta. Can $J$ Psychiatry. 2011;561:27-34.

21. Herman-Stahl MA, Krebs CP, Kroutil LA, et al. Risk and protective factors for methamphetamine use and nonmedical use of prescription stimulants among young adults aged 18 to 25. Addict Behav. 2007;325:1003-1015.

22. Solberg KE. Lebanese turn to drugs to treat mental-health problems. Lancet. 2008;372:1137-1138.

23. Storr CL, Lee GP, Derevensky JL, et al. Gambling and adverse life events among urban adolescents. J Gambl Stud. 2012;28:325-326.

24. Liu T, Maciejewski PK, Potenza MN. The relationship between recreational gambling and substance abuse/dependence: Data from a nationally representative sample. Drug Alcohol Depend. 2009;10011002:164-168.

25. Abu-Ras W, Ahmed S, Arfken CL. Alcohol use among U.S. Muslim college students: Risk and protective factors. J Ethn Subst Abuse. 2010;93:206-220.

26. Burazeri G, Kark JD. Alcohol intake and its correlates in a transitional predominantly Muslim population in southeastern Europe. Addict Behav. 2010;357:706-713.

27. Clausen T, Rossow I, Naidoo N, et al. Diverse alcohol drinking patterns in 20 African countries. Addiction. 2009;104:1147-1154.

28. Jessor R, Jessor SL. Problem behavior and psychosocial development: A longitudinal study of youth. New York, New York: Academic Press; 1977.

29. Hirschi T, Gottfredson M. The generality of deviance. In: Hirschi T, Gottfredson M, eds. The Generality of Deviance. pp. 1-22. New Brunswick, NJ: Transaction; 1994.

30. Slutske WS, Caspi A, Moffitt TE, et al. Personality and problem gambling: A prospective study of a birth cohort of young adults. Arch Gen Psychiatry. 2005;69:769-775.

31. Arria AM, Garnier-Dykstra LM, Caldeira KM, et al. Persistent nonmedical use of prescription stimulants among college students: Possible association with Attention Deficit Hyperactivity Disorder symptoms. $J$ Atten Disord. 2011;155:347-356.

32. Balodis IM, Potenza MN, Olstead MC. Recreational drug use and impulsivity in a population of Canadian undergraduate drinkers. Front Psychiatry. 2010;1:1-7.

33. Kazemi DM, Wagenfeld M, Van Horn KR, et al. Binge drinking among underage college students: Role of impulsivity and transtheoretical model. J Addict Nurs. 2011;22:193-199.

34. Kessler RC, Hwang I, LaBrie R, et al. DSM-IV pathological gambling in the National Comorbidity Survey Replication. Psychol Med. 2008;38: $1351-1360$.

35. McBride J, Derevensky J. Internet gambling behavior in a sample of online gamblers. Int J Ment Health Addict. 2009;7:149-167. 
Copyright of American Journal on Addictions is the property of Wiley-Blackwell and its content may not be copied or emailed to multiple sites or posted to a listserv without the copyright holder's express written permission. However, users may print, download, or email articles for individual use. 